\title{
Out with the Old or Out with the New: The Uncertain Role of Entrepreneurship in Developing Countries in the Post-COVID-19 Context*
}

\author{
Rami Abdelkafi ${ }^{1}$, Salim Refas ${ }^{2}$ \\ ${ }^{1}$ Islamic Development Bank Institute, Jeddah, Saudi Arabia \\ ${ }^{2}$ Istanbul Zaim University, Istanbul, Turkey \\ Email: rabdelkafi@isdb.org, refas.salim@std.izu.edu.tr
}

How to cite this paper: Abdelkafi, R., \& Refas, S. (2021). Out with the Old or Out with the New: The Uncertain Role of Entrepreneurship in Developing Countries in the Post-COVID-19 Context. Theoretical Economics Letters, 11, 1002-1019. https://doi.org/10.4236/tel.2021.115064

Received: August 19, 2021

Accepted: October 26, 2021

Published: October 29, 2021

Copyright $\odot 2021$ by author(s) and Scientific Research Publishing Inc. This work is licensed under the Creative Commons Attribution International License (CC BY 4.0).

http://creativecommons.org/licenses/by/4.0/

\begin{abstract}
The promotion of policies and initiatives that support job creation through entrepreneurship in developing countries is at the heart of the 2030 sustainable development goals (SDG) agenda, and, in particular, SDG 8 and 9. Yet, entrepreneurship remains an abstract concept difficult to define and comprehend, and the literature on entrepreneurship has been developed mostly in a developed country context. In the current global context, dominated by the dramatic impact of the COVID-19 pandemic, the relevant policies to be adopted by developing countries to face the socioeconomic consequences of the pandemic must be identified and analyzed. One of the main concerns of these policies is unemployment. The simultaneous supply and demand shocks caused by the pandemic have raised calls for an unprecedented level of public intervention in both developing and developed countries to prevent massive unemployment and chains of bankruptcies. The objective of this paper is to study the role of entrepreneurship in job preservation or job creation at the macroeconomic level. After reviewing different taxonomies of entrepreneurship and discussing motivations of entrepreneurs in a developing country context, the fundamental relationship between entrepreneurship, job creation, and macroeconomic performance in developing countries in both the pre- and post-COVID-19 contexts is analyzed. Using panel data for a sample of 24 countries members of the Organization of Islamic Cooperation (OIC) across the period 2009-2018, the paper demonstrates a U-shaped relationship between entrepreneurship and the level of economic development of nations, which translates into a negative correlation between economic
\end{abstract}

${ }^{\star}$ The views expressed in this article are purely those of the authors and may not in any circumstances be regarded as stating an official position of their respective institutions. 
growth and entrepreneurial dynamism for developing countries with per capita income below a certain limit. This proves that different phases of the economic cycle require different policies and promotion of entrepreneurship should therefore be adjusted to the economic conditions of each country.

\section{Keywords}

Entrepreneurship, COVID-19, Economic Recovery, Job Creation

\section{Introduction}

The promotion of policies and initiatives that support job creation through entrepreneurship in developing countries is at the heart of the 2030 Sustainable Development Goals (SDGs) agenda, and, in particular, SDGs 8 and 9. Yet, entrepreneurship remains an abstract concept difficult to define and comprehend. Entrepreneurship is frequently confused with self-employment, an important source of employment in developing nations. Perry et al. (2007) relate that self-employment may constitute up to $30 \%$ of the total employment in Latin America, for example. In a more comprehensive study across 74 developing nations, Gindling and Newhouse (2014) relate statistics for mainly low and middle-income groupings averaging $51.6 \%$ and $33.5 \%$, respectively, according to World Bank definitions. Owner-managers of small enterprises are therefore a critical category of entrepreneurs that must be considered in any attempt to provide and preserve jobs for all those in line with the SDG targets. However, the individual self-employed is not the only category of entrepreneurs in the economy. As Hagedoorn (1996) puts it, entrepreneurship can be broadly classified into two streams for research: one that looks on entrepreneurship at the level of individuals and the other that looks at corporate entrepreneurship and "intrapreneurship" especially at the level of large firms. Both categories are affected at times of crisis and this paper is specifically concerned about the drivers of successes and failures of entrepreneurship policies at a macroeconomic level in developing countries, with a focus on the post-COVID-19 context.

COVID-19 has unleashed an unprecedented economic crisis expected to affect the developing prospects of all nations across the globe for years to come. The "swift and massive shock of the coronavirus pandemic" since its advent in early 2020 is expected to be the harbinger of the deepest recession since the Second World War (Felsenthal, 2020). Entrepreneurial activities in all sectors have been affected by the simultaneous supply and demand shocks caused by the pandemic, and the World Economic Forum (WEF) estimates, for example, that the pandemic has forced more than $70 \%$ of start-ups to terminate full-time employee contracts. Yet, the degree and extent of the impacts of the recession on entrepreneurial activities are not well-understood. One of the reasons for that gap is the lack of methodological tools to link the aggregate macroeconomic ac- 
tivities of developing nations to the entrepreneurial intensity. This paper will, therefore, after a brief review of the drivers of entrepreneurship in the literature in the second section, discuss the relationship between national income and entrepreneurial levels in developing economies from a review of the literature in the third section. Against this backdrop, the fourth section of the paper discusses some stylized facts on the macroeconomic issues related to entrepreneurial success in developing nations and develops an empirical model that is calibrated and tested on a balanced sample of 24 member countries of the Organization of Islamic Cooperation (OIC) over the post-crisis period 2009-2018 to demonstrate the U-shaped relationship between national income and entrepreneurial levels. This has an important consequence when looking at the macroeconomic impacts of the COVID-19 recession on both entrepreneurial activity and employment in developing nations, and this is discussed in sections 6 and 7 with a brief theoretical review of the main drivers of the relationship between wages and employment levels. The policy options for developing nations with limited fiscal space and growing unemployment levels in the context of such a major recession are very limited, calling for great selectivity and a detailed understanding of the most efficient mechanisms to achieve job preservation or job creation targets despite challenges. The conclusion will hence propose some areas for further research and some candidate policy approaches worth considering given the research results presented in the previous sections.

\section{The Drivers of Entrepreneurship}

Despite the consensus on the role of entrepreneurship in economic growth, the interactions between entrepreneurs and their environment are very complex and difficult to comprehend. These interactions reflect the bidirectional relationship between entrepreneurs and their environment and the way they are also affected by several socio-economic factors in the economies where they operate. Over the years, economic theory has gradually incorporated additional factors in analyzing entrepreneurship as a driver of economic activity. Walia and Chetty (2020) differentiate between three main types of theories of entrepreneurship, namely the classical theories, the neo-classical theories, and the Austrian market process as illustrated in Figure 1. While the classical and neo-classical approaches focus on the actions undertaken by entrepreneurs for the production and distribution of goods and services, the Austrian approach is based on the knowledge that entrepreneurs possess about the economy.

Casson and Wadeson (2007) consider four approaches to define the entrepreneur based on his function, role, personal characteristics, and behavior. Function has to do with the action undertaken through innovation and risk taking, while role is related to the action as an investor owning capital and exploiting production factors. Personal characteristics and behavior are more related to attitudes and decision making. In this context, the entrepreneurial function determines his impact on the macroeconomic performance. 


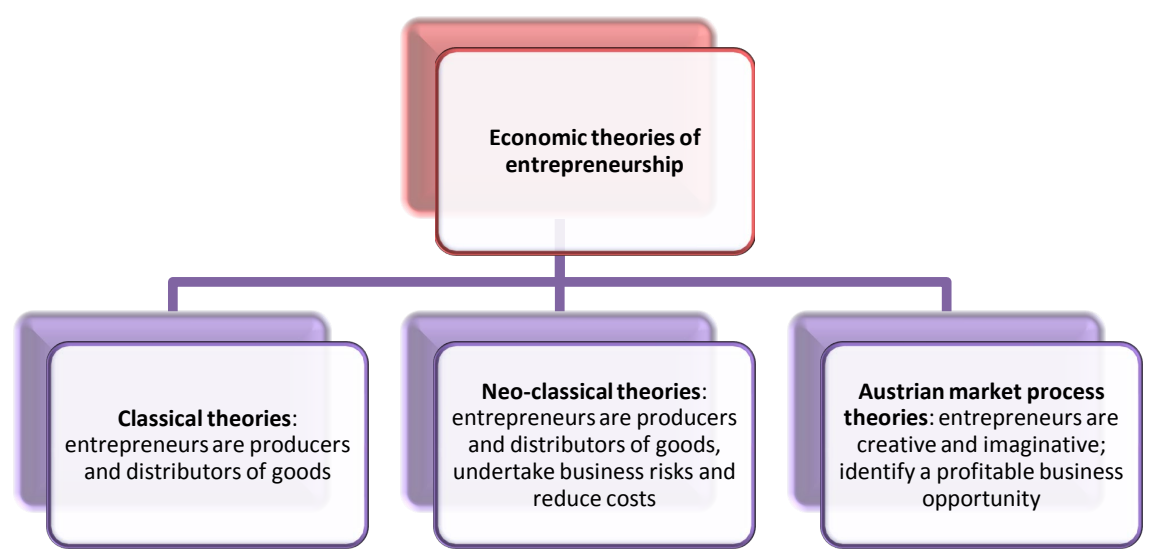

Figure 1. Economic theories of entrepreneurship. Source: Walia and Chetty (2020).

As an investment activity, entrepreneurship is based on the knowledge of the entrepreneur and on his ability to take a call regarding existing opportunities to overcome the challenges resulting from his decision. At the same time, opportunities are the results of changes in several socio-economic conditions influencing the demand and supply conditions. For Casson and Wadeson (2007), the fact that the environment is volatile implies that opportunities are never exhausted, and what is limited is just the stock of projects available to entrepreneurs. In studying the determinants of entrepreneurship, this leads to distinction between the internal factors related to the entrepreneur's skills and capabilities and the external factors related to his environment and the way the environment affects his decisions.

The question of how the environment affects entrepreneurship has been a subject of divergence between economists and has triggered many empirical studies to identify the critical factors for success and failure in different contexts. del Olmo-García et al. (2020) distinguish between economic environment and institutional environment and their contribution to the failure of self-employed entrepreneurs in the eurozone. Their results demonstrate that in addition to economic factors, the culture and perceptions of society about entrepreneurship are significant factors in reducing entrepreneurship failure. Furthermore, their study shows that the quality of formal institutions (including protection of property rights, the quality of the legal system etc.) plays a key role in reducing the failure of entrepreneurship. Interestingly, Devece et al. (2016) show that in Spain, while innovation remains the key success factor, opportunity-driven entrepreneurship tends to perform much better than necessity-driven entrepreneurship in periods of recession.

Overall, studying entrepreneurship is complex in the sense that it implies analyzing the economic, social, and institutional factors responsible for the success and failure of any entrepreneurial activity. Recently, an increasing number of studies have been interested in the level of entrepreneurship in different economic phases. In that sense, in addition to the multidisciplinary aspect of entrepreneurship, the results of any study are conditioned by the context of the study. 
For example, while several studies have been able to assess the situation in the context of developed countries (Maritz et al., 2020; Galindo-Martín et al., 2021; Devece et al., 2016; del Olmo-García et al., 2020), studies in the context of developing countries have been very limited until now (Mendoza et al., 2021; Omri, 2020). Lastly, the nature of entrepreneurship is very important to assess the sustainability of its impact on economic growth. In fact, opportunity entrepreneurship is driven more by innovation and the opportunities it creates in the economy. Hence, this kind of entrepreneurship, which is more predominant in developed countries, can leave a lasting impact on economic growth by creating added value and more jobs, as well as triggering other innovations through competition. However, necessity entrepreneurship is in general driven by the lack of alternatives and by the low level of employment created by the economic activity. In this context, this kind of entrepreneurship can be terminated as soon as some opportunities are created and become available to the entrepreneurs.

In addition to the distinction between developed and developing countries, some recent researches have studied the dynamics of entrepreneurship in periods of crisis (Maritz et al., 2020; Galindo-Martín et al., 2021; Devece et al., 2016). Similarly, the current crisis created by the COVID-19 pandemic has triggered some questions about the potential impacts on entrepreneurship, as well as the potential opportunities this crisis has created. For example, according to the World Economic Forum (WEF), the pandemic has forced more than 70\% of start-ups to terminate full-time employee contracts. At the same time, the WEF considers that the pandemic has also created new opportunities through the creation of new needs and the opening of new markets related to the attempts to cope with the challenges posed by the new modes of life.

\section{Relationship between National Income and Entrepreneurship Levels}

Since 2004, the Global Competitiveness Report published by the World Economic Forum (WEF) ranks countries based on the Global Competitiveness Index (GCI) developed by Xavier Sala-i-Martin and Elsa V. Artadi. In the framework of the GCI, consisting of over 110 variables for each country, the countries are classified into three stages of economic development (factor-driven, efficiency-driven, and innovation-driven), each implying a growing degree of complexity in the operation of the economy. The GCI in its new version since 2004 has partially addressed some of the caveats of the previous GCI framework, which was deficient at several levels, including issues of methodology, consistent bias, qualitative vagueness, incorrectness, or redundancy (Lall, 2001), but methodologically, the framework of the GCI still suffers from multiple methodological issues including, for example, obvious issues of endogeneity and causality (Workie and Hekelová, 2016). Yet, the GCI has now established itself as a global indicator of the ability of countries to provide prosperity to their citizens and is constantly adopted by policymakers and development institutions to assess the 
successful macroeconomic performance of nations. As a side effect to this convergence of the global discourse on development prospects of nations, the paradigm shift from managerial to entrepreneurial capitalism, which once characterized the US economy (Baumol et al., 2007; Baumol, 2009), has now extended to how "good" or "bad capitalism" can be defined for all nations (Baumol, 2009).

The economic literature on the relationship between entrepreneurship, economic development, and growth is expansive. As Hagedoorn (1996) puts it, this literature can be broadly classified into two streams of research: one looking at entrepreneurship at the level of individuals and the other looking at corporate entrepreneurship and "intrapreneurship" especially at the level of large firms. Hagedoorn (1996) also explains how this dichotomy is created in reference to early and late works of Schumpeter on innovation. Quadrini (2009) discusses, however, an important definition issue pertaining to such research: the entrepreneur can be alternatively defined as a self-employed individual, which is generally the focus of papers dealing with occupational choice; other studies focus on the ownership of a business with an active management role to define entrepreneurship; finally, studies concerned with corporate entrepreneurship usually associate entrepreneurial activity to innovation, along the Schumpeterian lines of thought, therefore not really imposing ownership of occupational choice in the definition of entrepreneurs in the firms. This has an important consequence when researching the macroeconomic impact of entrepreneurial activity in developing nations. Indeed, as Quadrini (2009) reminds us when looking at recent macroeconomic papers published on entrepreneurship, due to the financing constraints, the scale of entrepreneurial businesses in developing nations tends to be smaller, and in fact self-employment is often the sole option for large segments of population entering the job market in search of an occupation. Against this backdrop, the whole body of literature on corporate entrepreneurship and the long-term impact of innovation in the economy arguably loses relevance in the developing country context.

In fact, in a developing country context, the mechanisms through which entrepreneurship levels under the first category (individual entrepreneurs) affect national economies are still vastly obscure, and the main obstacle to that understanding is the lack of entrepreneurship data to reflect the specific stage of development of each nation (Acs et al., 2008). A frequently cited relationship, however, is demonstrated in Wennekers et al. (2005), wherein there stands a $\mathrm{U}$-shaped relationship between entrepreneurship and the level of development of nations: in low-income countries, entrepreneurship is generally negatively correlated with economic development while in high-income countries, the correlation is positive. Such findings, although not explicit about the direction of causality between entrepreneurship levels and national economic development, tend to support national development strategies attracting foreign direct investment in lower income countries while policies that encourage entrepreneurship and innovation such as high-growth startups are expected to yield nation-wide 
spillover effects in higher income countries only. This has important consequences on policy options, especially at times of recession, as will be discussed in the last section of this paper.

\section{Stylized Facts on Entrepreneurial Activity and Outcome Levels in Developing Nations}

Even in the absence of relevant quantitative models and theoretical frameworks, several stylized facts can be derived from data on developing nations and the levels of self-employment or entrepreneurial activity. First of all, self-employment is an important source of employment in developing nations. Perry et al. (2007) relate that it may constitute up to $30 \%$ of total employment in Latin America, for example. In more comprehensive studies across 74 developing nations, Gindling and Newhouse (2014) relate statistics for mainly low and middle-income groupings averaging $51.6 \%$ and $33.5 \%$, respectively, according to World Bank definitions (see Table 1 below).

The fact that one out of two workers or one out of three workers, respectively, in low income or lower middle-income countries is self-employed is in itself a major finding. Gindling and Newhouse (2014) analyze the type and quality of jobs that these self-employed workers occupy and their relative success. For example, the proportion of self-employed workers is significantly higher in agricultural jobs, reaching $60 \%$ or $47 \%$, in the sample countries of the study for low income or lower middle-income groups, respectively. More importantly, the authors are able to demonstrate a clear "order" in such countries between employment categories, and wage and salary employees are revealed to be better off in particular than own-account workers.

This leads to the second stylized fact regarding self-employment and entrepreneurial activity in developing nations: the heterogeneity of the trajectories of entrepreneurs with respect to their growth potential. Gindling and Newhouse (2014) refer to two main groups among the self-employed workers: one group of self-employed with "limited growth prospects who either are self-employed by necessity, due to the lack of wage employment opportunities, or have voluntarily chosen self-employment over wage employment" and, in contrast, a higher tier of self-employed consisting of "innovative, successful entrepreneurs with greater potential and ambition for growth". This echoes the necessity-motivated entrepreneurship (NME) and the opportunity-motivated entrepreneurship (OME) in Bennett and Nikolaev (2019). A key conclusion of Gindling and Newhouse (2014) along these lines is that only a small proportion of the entrepreneurs in the first group (NME) are successful. Using different definitions of success (job creation or per capita consumption in the household), less than a third of the entrepreneurs are considered successful in the sample low income and lower middle-income countries. In this paper, this will be referred to as the "entrepreneurship trap" whereby self-employed individuals driven by necessity are not able to actually grow, accumulate capital or exit poverty and deprivation. 
Table 1. Proportion of workers by occupational status by country, region, and income.

\begin{tabular}{ccccc}
\hline Income level $^{\mathrm{a}}$ (\# of countries in sample) & Wage and salary employee & Non-paid employee & Employer & Own account \\
\hline Low income (18) & 25.2 & 21.6 & 1.6 & 51.6 \\
Lower middle income (31) & 46.0 & 18.2 & 2.4 & 33.5 \\
Upper middle income (25) & 73.1 & 4.2 & 4.2 & 18.6 \\
High income (24) & 85.9 & 1.0 & 3.7 & 9.3 \\
\hline
\end{tabular}

${ }^{2}$ Low income less than 1006 - 2010 dollars; lower middle income 1006 - 3975 dollars; upper middle-income 3976 - 12,275 dollars; high income greater than 12,275 dollars. Source: Gindling and Newhouse, 2014.

A third major fact relates to the massive exclusion of individual entrepreneurs from the formal economy in low income and lower middle-income countries. The mechanisms are described in Auriol (2013). Starting from the well-known fact that the shadow economy (or informal sector) has a significant size in low income and lower-income countries, representing for example as reported by (Enste and Schneider, 2003) up to $39 \%$ of the economy across a sample of 76 developing nations, Auriol (2013) explains how several administrative, economic or cultural factors prevent entrepreneurs from entering the formal economy, even when successful. This implies various adverse consequences among which two are of significance in the context of this study: entrepreneurs in the informal sectors are exposed to weakened property rights and heightened risks, and at the same time, due to the heavy social costs incurred on them by the forced mutual help they have to extend to family and relatives in replacement of social safety nets, there is a net loss in job and wealth creation due to the inefficient allocation of resources.

A fourth major fact, especially in the context of development policies aiming at fostering employment, is what Schoar (2009) calls the divide between subsistence and transformational entrepreneurship. After reminding of the renewed expectations in recent years that entrepreneurship will spur the development of poor nations, Schoar (2009) rightfully observes that "most policy makers as well as economic researchers treat entrepreneurs as a homogeneous group of actors that are uniformly affected by economic conditions or policy interventions" and in doing so they fall to keep in mind a significant characteristic of low income and lower-middle income countries: the very low prevalence of medium-sized companies. The evidence is scanty to show why a very large number of tiny firms are unable to graduate into medium-sized firms which in the context of developed nations are the primary employer and contributor to economic success, but the facts are harsh and clear: the size distribution of firms in low-income and lower middle-income countries is bimodal with many tiny firms and few large firms. In this context, the characteristics of transformational entrepreneurs and the levers to support them are not well-identified, and they are not rightfully stimulated to boost the economy. Another dimension of this problem refers to the largely reported issue of skill mismatch to support successful entrepreneurs in their growth stage as discussed for example in Lee (2013). The following Table 2 summarizes these four main facts reported in the literature about entrepreneurial activity and income levels. 
Table 2. Main stylized facts on entrepreneurial activity and income levels in developing nations.

1. Prevalence of necessity-motivated entrepreneurship

2. Heterogeneity of the trajectories of entrepreneurs with respect to their growth potential

3. Exclusion of individual entrepreneurs from the formal economy

4. Missed opportunities to support transformational entrepreneurship and skill mismatch

Source: Authors.

\section{Quantitative Model and Empirical Results}

In this section, an empirical analysis is conducted to test the relationship between entrepreneurial activity and economic growth in some members of the Organization of Islamic Cooperation (OIC). The choice of the sample was motivated by the availability of data. As mentioned earlier, this availability of data was one of the main reasons of the dominance of studies on developed countries compared to developing countries. We conduct a panel data analysis on a balanced sample of 24 OIC countries over the post-crisis period 2009-2018.

In addition to the availability of data, the choice of entrepreneurship indicator has been one of the divergence factors between researchers. The data provided by the Global Entrepreneurship Monitor (GEM) has allowed for more empirical research on entrepreneurship in the last twenty years. However, the structure of the data presented by the GEM makes a panel data analysis unfeasible given the disparity of periods covered by the surveys between countries.

Following Omri (2020), we used the new business density as an indicator of entrepreneurship, to estimate the following model with $i=1, \cdots, 24$ representing countries and $T=1, \cdots, 10$ for years included in the sample:

$$
Y_{i t}=\beta_{0}+X_{i t}^{\prime} \beta+\varepsilon_{i t}
$$

where $Y_{i t}$ represents the dependent variable, in our case entrepreneurship. $X_{i t}$ is a $K$-dimensional vector of explanatory variables, $\beta$ a $(K \times 1)$ vector of coefficients independent of $i$ and $t$ and $\varepsilon_{i t}$ the error term varying over $i$ and $t$.

The dependent variables included in the model are as follows:

- Economic growth is represented by the Gross Domestic Product (GDP) per capita, which is based on purchasing power parity (PPP) and converted to constant 2017 international dollars.

- Following Galindo-Martín et al. (2021), we include two variables representing the social climate, which can affect entrepreneurship. These variables are the Human Development Index (HDI) and unemployment (U).

- Government effectiveness is included to reflect the role of institutions in developing entrepreneurship (Galindo-Martín et al., 2021; Omri, 2020). This variable captures perceptions of the quality of public services, the quality of the civil service, the degree of its independence from political pressures, the quality of policy formulation and implementation, and the credibility of the government's commitment to such policies ${ }^{1}$.

${ }^{1}$ https://databank.worldbank.org/source/worldwide-governance-indicators 
Table 3 below describes the different variables used in the model and the sources of the data:

Based on that, we have estimated the following equation using a fixed effect mode. This choice has been based on the Hausman test:

$$
\mathrm{ENTRE}_{i t}=\beta_{0}+\beta_{1} \mathrm{LGDPPC}_{i t}+\beta_{2}\left(\mathrm{LGDPPC}_{i t}^{2}+\beta_{3} \mathrm{U}_{i t}+\beta_{4} \mathrm{GE}_{i t}+\beta_{5} \mathrm{HDI}_{i t} \varepsilon_{i t}(2)\right.
$$

In order to confer more homogeneity on our sample, we chose to test the model on the sample excluding rich GCC countries. Table 4 demonstrates the results of the estimations of Equation (2) on the whole sample of countries and on the sample excluding GCC countries. Comparing different estimations on both samples indicates that the non-linear model including a quadratic term for the GDP per capita is more adapted to the relationship between entrepreneurship and economic growth. Our results are the following:

Our results show that the coefficient related to unemployment is statistically insignificant, although it has the expected sign showing a negative impact of unemployment on entrepreneurship in all estimations. For the variable GE, related to government effectiveness, the coefficient is sensitive to the sample specification. While it has the opposite sign with a significance level of $10 \%$ in the whole sample, it is positive and significant in the sample excluding the GCC countries, expressing the importance of the impact that a better quality of public services can have on entrepreneurship in developing countries. A deeper investigation of this impact by using different indicators of government actions would be interesting; however, this is beyond the scope of this paper. The HDI has a significant positive impact on entrepreneurship with a $1 \%$ significance level in the whole sample. However, this impact turned insignificant in the sample excluding the GCC countries. One possible explanation of this result lies in the need for decomposing this index and studying the role of its different components. For example, it would be interesting to differentiate between the different levels of education in the context of developing countries and observe their roles in entrepreneurship development.

Furthermore, our results show that the quadratic model confirms the U-shape of the relationship between entrepreneurship and economic growth, as evidenced by the negative and significant coefficient of the GDP per capita and the significant positive coefficient of the square of GDP per capita in both samples. Another interesting way to look at the relationship between entrepreneurship and economic development is to study the causality between the two variables. As mentioned earlier, one of the main complexities in entrepreneurship lies in the fact that this variable participates in economic growth, and at the same time it is also affected by several economic factors related to economic development. Based on that, we tried to perceive the causal relationship between entrepreneurship and economic growth by applying a Granger causality test on the variables ENTRE and LGDPPC on both samples. The results are as shown in Table 5 below: 
Table 3. Definition and sources of variables.

\begin{tabular}{ccccc}
\hline Variable & Sign & Definition & Source \\
\hline Entrepreneurship & (ENTRE) & New business density (new registrations per 1000 people ages 15 - 64) & WDI \\
Economic growth & LGDPPC & Natural Log of the GDP per capita PPP (constant 2017 international \$) & WDI \\
Unemployment & U & Unemployment, total (\% of total labor force) & WDI & WGI \\
Government effectiveness & GE & Government Effectiveness & UNDP \\
Human Development Index & HDI & Human Development Index & \\
\hline
\end{tabular}

Table 4. Results of estimation of Equation (2).

\begin{tabular}{|c|c|c|c|c|}
\hline \multirow{3}{*}{$\begin{array}{l}\text { Variables } \\
\text { Constant }\end{array}$} & \multicolumn{2}{|c|}{ Whole sample } & \multicolumn{2}{|c|}{ Sample excluding GCC } \\
\hline & \multicolumn{2}{|c|}{ ENTRE } & \multicolumn{2}{|c|}{ ENTRE } \\
\hline & $\begin{array}{l}-5.23 \\
(-1.31)\end{array}$ & $\begin{array}{c}27.66^{* *} \\
(2.18)\end{array}$ & $\begin{array}{c}-4.58^{* * *} \\
(-2.06)\end{array}$ & $\begin{array}{c}25.15^{* * *} \\
(3.34)\end{array}$ \\
\hline LGDPPC & $\begin{array}{l}-0.03 \\
(-0.05)\end{array}$ & $\begin{array}{c}-7.79^{* * *} \\
(-2.69)\end{array}$ & $\begin{array}{c}0.41 \\
(1.23)\end{array}$ & $\begin{array}{l}-6.7^{* * *} \\
(-3.81)\end{array}$ \\
\hline LGDPPC $^{2}$ & & $\begin{array}{l}0.44^{* * *} \\
(2.73)\end{array}$ & & $\begin{array}{c}0.42^{* * *} \\
(4.12)\end{array}$ \\
\hline $\mathrm{U}$ & $\begin{array}{l}-0.03 \\
(-1.15)\end{array}$ & $\begin{array}{l}-0.04 \\
(-1.31)\end{array}$ & $\begin{array}{l}-0.01 \\
(-1.03)\end{array}$ & $\begin{array}{l}-0.01 \\
(-1.00)\end{array}$ \\
\hline GE & $\begin{array}{l}-0.02 \\
(-1.13)\end{array}$ & $\begin{array}{l}-0.37 \\
(-1.67)\end{array}$ & $\begin{array}{c}0.54 \\
(4.02)\end{array}$ & $\begin{array}{c}0.51^{\star * \star} \\
(4.01)\end{array}$ \\
\hline HDI & $\begin{array}{c}10.16^{\star * *} \\
(4.15)\end{array}$ & $\begin{array}{c}10.34^{\star * *} \\
(4.29)\end{array}$ & $\begin{array}{c}3.56^{* * *} \\
(2.06)\end{array}$ & $\begin{array}{c}3.06 \\
(1.84)\end{array}$ \\
\hline Number of observations & 240 & 240 & 190 & 190 \\
\hline$R^{2}$ & 0.84 & 0.85 & 0.90 & 0.91 \\
\hline
\end{tabular}

Note: The $t$ value is bracketed, and ${ }^{* * *}$ and ${ }^{* *}$ indicate significance at the $1 \%$ and $5 \%$ levels, respectively.

Table 5. Granger causality test between entrepreneurship and growth.

\begin{tabular}{ccccc}
\hline & \multicolumn{2}{c}{ Whole Sample } & \multicolumn{2}{c}{ Sample excluding GCC } \\
\hline Null Hypothesis & F-Statistic & Prob. & F-Statistic & Prob. \\
\hline LGDPPC does not Granger Cause ENTRE & 5.93 & 0.01 & 5.51 & 0.02 \\
ENTRE does not Granger Cause LGDPPC & 0.3 & 0.58 & 3.4 & 0.06 \\
Observations & & 216 & & 171 \\
\hline
\end{tabular}

The results presented in Table 5 prove that in both samples, the causality is only from the GDP per capita to entrepreneurship. The causality from entrepreneurship to growth is insignificant. This could be explained by the quality of entrepreneurship created in developing countries. While this entrepreneurship can be created following an increase in economic growth, it fails to drive economic growth in these countries. As mentioned above, necessity-based entrepreneurship is dominating the economies of developing countries. Lack of opportunities and innovation in developing countries makes entrepreneurship less effective in developing countries in comparison to developed countries.

Before concluding, the next sections will now discuss some theoretical con- 
siderations regarding the possible impacts of recession on employment levels and wages, due to the evidenced relationship between entrepreneurial activity and economic growth on the development policy options for the concerned countries.

\section{What Are the Possible Impacts of Recession on Employment Levels and Wages?}

In spite of the appeal of innovation and entrepreneurship as drivers of development in poor nations, the challenges standing in the way of fulfilling the Schumpeterian development promise of creative destruction at a macroeconomic level in low-income developing nations are many. These challenges grow into major risks at times of crisis. Massive levels of unemployment are one of the most common and immediate consequences of a sudden drop in trade or a recession in the economy (Loayza et al., 2009). With a constant or decreasing supply of labor, for example in mature economies, this is already a very critical consequence of economic crises that has the potential of stirring up social unrest and regime change, and profound socioeconomic changes have been unfortunately observed during the course of the 20th century in both developed and developing nations. However, this is further heightened in factor-driven labor-rich economies, which naturally supply an even higher number of job seekers in the market. In this context, one may be tempted to simplistically describe the dilemma that decision makers are faced with: either jobs of current workers should be saved on a priority basis with the limited levers available for government intervention or the onus should be on supporting the economy to rapidly transform to be able to create jobs for both the job seekers entering the market and the current workers who will inevitably lose their jobs as a result of the crisis. The two dynamics are simplistically described in the graphs below. In both graphs, equilibrium employment level in the economy is defined as the intersection of a price-setting curve, which depicts the aggregate demand for jobs from the economy at the production frontier, and the wage-setting curve, which is the occupational demand for wage-jobs by job seekers (against the available alternatives of unemployment or other activities). Since the first effect of the crisis is the immediate impact on the revenues of firms and their ability to pay salaries, the price-setting curve is immediately shifted downwards and the equilibrium employment level is shifted from wh to wl: a net amount of jobs (wh - wl) is immediately lost in the economy. The dashed area 1 in Figure 2 below represents the net income lost in the immediate term at an aggregate level by the working class due to these job losses.

The secondary impact of the recession subsequent to the crisis is to shift the wage-setting curve downwards, especially for low-pay workers. This effect is particularly marked in developing countries with weak social protection structures (Arranz et al., 2020). Interestingly, and as pictured in Figure 3 at an aggregate level, this could generate a positive employment outcome since the lower 
wages due to lower expectations from job seekers as well as the entry of new job seekers in the market may lead to a higher equilibrium employment level wg. In practice, achieving this new maximum employment level will pose a challenge for the economy requiring transformation of jobs and recovery measures. The net amount of jobs created ( $\mathrm{wg}-\mathrm{wl}$ ) will possibly recover partly or fully the net amount of jobs (wh - wl) that were immediately lost. At the same time, the aggregate income impact is pictured by the net difference between the diamond-filled area 2, which is the additional aggregate income due to job creation, and the dashed area 3 , which is the aggregate income lost due to salary reduction.

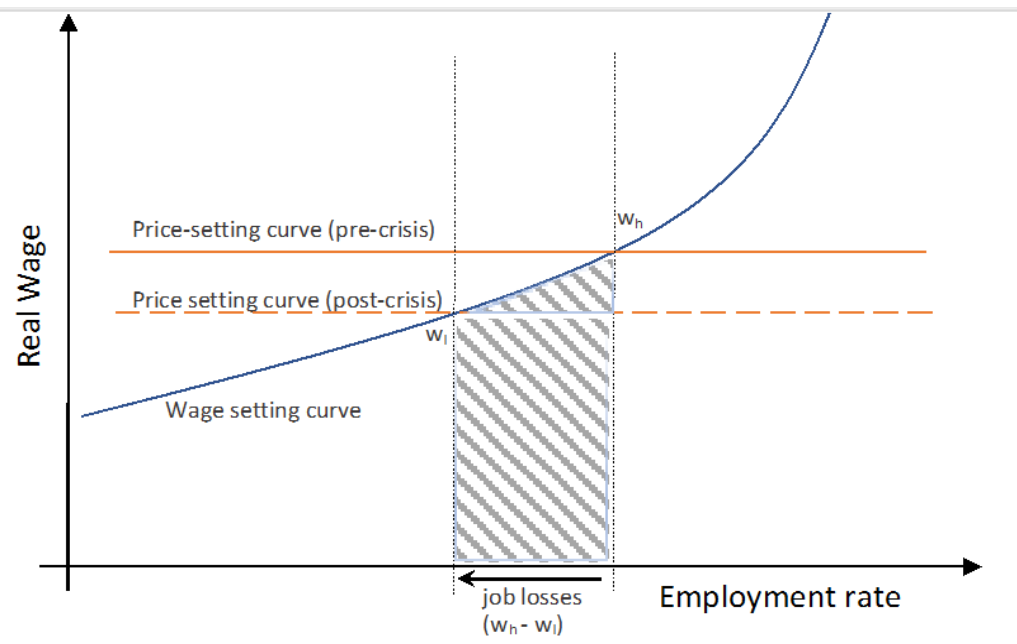

Figure 2. Immediate employment impact of the recession on job supply and demand equilibrium. Source: Authors.

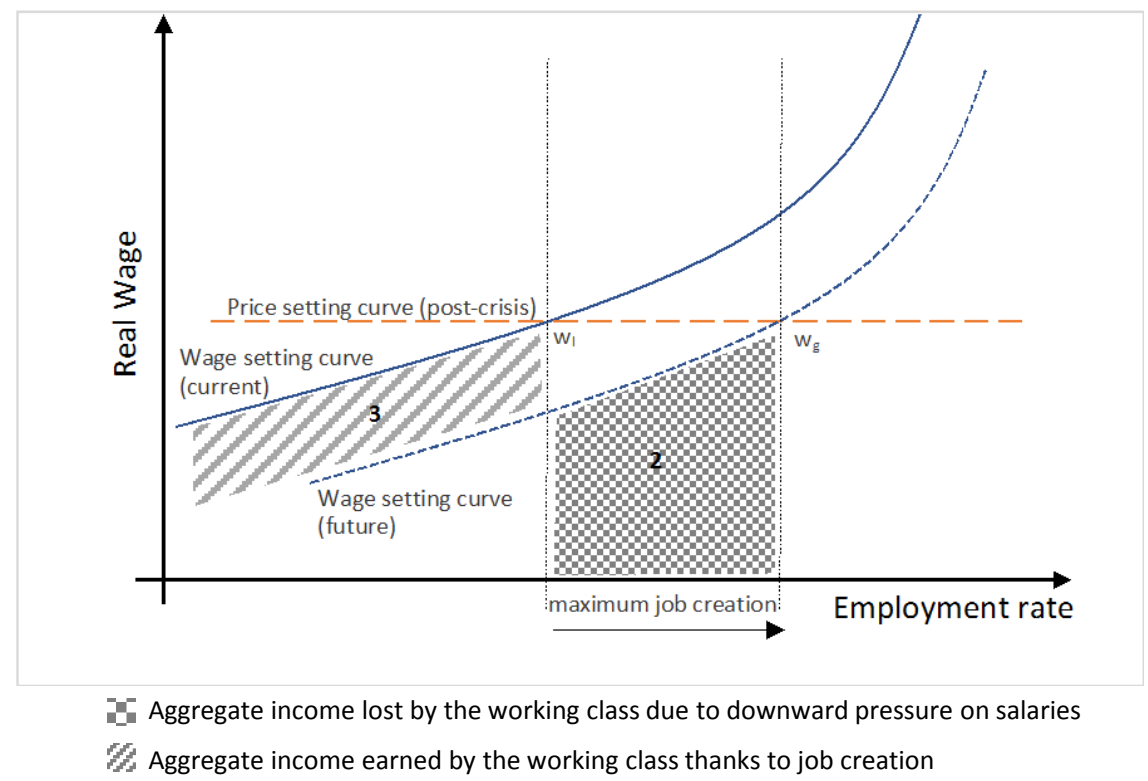

Figure 3. Medium-term employment impact of the recession on job supply and demand equilibrium. Source: Authors. 
This analytical framework must however be complemented to account for the role of entrepreneurship and self-employment when managers or workers do not simply enter the job market as price-takers of the wages offered by the available opportunities but in fact create their own jobs out of necessity or opportunity (Bennett and Nikolaev, 2019). Three populations are especially concerned in the graphs above: 1) in the immediate term, the population which lost their jobs as a consequence of the recession (wh - wl) in case there is no relief policy to immediately preserve their jobs or provide them with temporary wage support (necessity-motivated entrepreneurs) as pictured by area 1 in Figure 2; 2) in the medium term, the job seekers at the right of the equilibrium level wg," who do not occupy the jobs at the wages offered by the market, because it is below the minimum expected wage for the concerned jobs (necessity-motivated entrepreneurs); and 3) in the medium term or immediate term, any employed individual who has a higher expectation from an entrepreneurial venture than the equilibrium wage offered by the market (opportunity-motivated entrepreneurs). An analytical challenge posed by the uncertainties related to wage-demand functions of the entrepreneurs, who intrinsically take risks by becoming entrepreneurs but have high-reward expectations, is to reveal their wage (or profit) expectations. Consequently, among the three populations just described the quantity of necessity-motivated or opportunity-motivated entrepreneurs with higher expectations that equilibrium wages cannot be pictured in Figure 3. The next sections will discuss however how different trajectories can be expected for these three populations of entrepreneurs, and how this will in turn lead to differentiated aggregate outcome at the macroeconomic level.

\section{The Difficult Timing of Policy Interventions}

The question of the relevant policy interventions for preservation and creation of jobs in times of recession at a macroeconomic level has two main dimensions: an effectiveness dimension and a time dimension. Due to the specifics of the agricultural jobs in a developing country context, these policies should be ideally treated differentially for agricultural and non-agricultural jobs. However, for the sake of simplification, this paper will present the candidate measures for job preservation and creation along two timelines only: short-term relief and longer-term recovery measures. The proposals are derived from Loayza et al. (2009), who discuss the time dimension of the policy interventions of developing nations to limit the detrimental effects of the economic crisis caused by the COVID-19 pandemic.

Table 6 summarizes the most relevant recommendations along two dimensions: labour supply and consumption or, in other words, policy interventions on the supply and demand side of the economy. The "swift and massive shock of the coronavirus pandemic" since its advent in early 2020 is expected to lead to the deepest recession since the Second World War (Felsenthal, 2020). This is partly because the simultaneous demand and supply shocks from the pandemic 
Table 6. Candidate measures for job creation and job preservation during recession.

\begin{tabular}{|c|c|c|}
\hline & Relief measures & Recovery Measures \\
\hline \multirow{5}{*}{$\begin{array}{l}\text { Self-employed } \\
\text { Businesses }\end{array}$} & Direct income support to vulnerable & $\begin{array}{l}\text { Formalization of jobs, direct income support, skill support programs, and job } \\
\text { transformation programs }\end{array}$ \\
\hline & $\begin{array}{l}\text { populations (e.g., cash transfers) } \\
\text { Temporary tax cuts and moratoriums }\end{array}$ & $\begin{array}{l}\text { Public loans and guarantees for capital investments, wage support, vocational } \\
\text { training programs, and targeted subsidies }\end{array}$ \\
\hline & on debt repayments & Business transformation programs (digitalization, sector transformation, etc.) \\
\hline & $\begin{array}{l}\text { Public loans and guarantees, and wage } \\
\text { subsidies }\end{array}$ & $\begin{array}{l}\text { Partial/temporary nationalization programs to support employment and prevent } \\
\text { large bankruptcies }\end{array}$ \\
\hline & & National/local preference programs to support local industries/traders \\
\hline $\begin{array}{l}\text { Demand-side } \\
\text { interventions }\end{array}$ & $\begin{array}{l}\text { Government expenditures, interest-rate cuts, } \\
\text { and widening lending facilities to banks }\end{array}$ & $\begin{array}{l}\text { Macroeconomic stimulus packages, fiscal stimulus, public investment, and targeted } \\
\text { sector interventions }\end{array}$ \\
\hline Challenges & $\begin{array}{l}\text { Fiscal space, household targeting for } \\
\text { middle-income countries }\end{array}$ & $\begin{array}{l}\text { Financial market response to interest cuts, transmission to real economy, small } \\
\text { fiscal multiplier, knowledge economy, and time-lag of the public interventions }\end{array}$ \\
\hline Timeline & Immediate & Medium term \\
\hline
\end{tabular}

Source: Loayza et al. (2009) and Authors.

are unprecedented since the Second World War, or even the Great Recession according to certain commentators.

The challenges pertaining to the timing of job preservation and creation policies, therefore, become extremely challenging in the context of this crisis for developing countries with limited fiscal space, weak financial markets, small fiscal multipliers, and massive demographic pressure.

\section{Conclusion}

This paper is primarily about the relationship between entrepreneurship, job creation or preservation, and macroeconomic performance in developing countries. This complex relationship, fundamental in the context of the sustainable development agenda, is even more important in the context of massive supply and demand shocks caused by the COVID-19 pandemic. The primary conclusion of this paper is that in developing countries, the relationship between entrepreneurship and economic growth is determined by the current stage of economic development: due to multiple challenges, the relationship is weak in the lower income economies while in higher income economies GDP growth translates successfully into more entrepreneurial activity.

Other findings of the study include the observed prevalence of necessity-motivated entrepreneurship in developing countries, which starkly contrasts with the corporate or individual entrepreneurial activity in high-income countries, predominantly opportunity-driven. In addition, the trajectories of entrepreneurs with respect to their growth potential are found to be very variable and a majority of entrepreneurs in developing countries context are constrained in their growth potential due to administrative, economic or cultural factors, which translates into lower aggregate economic performance at a macroeconomic level. The observed exclusion of individual entrepreneurs from the formal economy in 
countries at a lower development stage poses significant socioeconomic challenges at the macroeconomic level, especially at times of crisis. Finally developing countries are found to effectively miss opportunities to support transformational entrepreneurship due to financing constraints or skill mismatch in particular.

The empirical study demonstrates that a non-linear model including a quadratic term for the GDP per capita is most adapted to map the relationship between entrepreneurship and economic growth at a macro-economic level in a developing country context. The model is calibrated and tested using panel data for a sample of OIC member countries. The model successfully demonstrates the quadratic relationship and the sample also shows a unidirectional causality going from the GDP per capita to entrepreneurship. This demonstrates that the low-quality entrepreneurship created in developing countries, in most cases necessity driven, is hardly a strong pillar of economic growth or recovery post-recession. In the context of an immediate and significant impact of the COVID-19 crisis on employment in developing countries, the findings of this paper would question therefore a one-size-fits-all policy-making approach which leverages on entrepreneurship or innovation to sustain or create jobs for economies in recession. The dilemma between protecting the existing fragile jobs and adopting entrepreneurship development policies is very acute and the right policy approach highly depends on the stage of development of the country. In this context, a menu of candidate policy interventions most promising to address the employment challenges in developing countries is briefly discussed in the last section.

This paper can constitute a starting point for further research on the same subject and in particular on the relevant approaches to fight unemployment through targeted and multi-cycle entrepreneurship policies in a developing country context. One of the main limitations of this research is the absence of disaggregated information to characterize the demand functions at a micro-level of necessity-motivated or opportunity-motivated entrepreneurs in a pre-crisis or post-crisis context. Understanding how the expectations of entrepreneurs are affected by the aggregate unemployment levels in particular is critical to understand whether the appetite for entrepreneurship grows or reduces in a context of employment crisis for wage jobs. Further research efforts are also required to characterize with more depth the relationship between entrepreneurial activity and economic growth and reveal in particular the mechanism by which GDP growth effectively leads to more successful entrepreneurship for higher income countries.

\section{Conflicts of Interest}

The authors declare no conflicts of interest regarding the publication of this paper. 


\section{References}

Acs, Z. J., Desai, S., \& Hessels, J. (2008). Entrepreneurship, Economic Development and Institutions. Small Business Economics, 31, 219-234. https://doi.org/10.1007/s11187-008-9135-9

Arranz, J. M., Fernández-Macías, E., \& García-Serrano, C. (2020). Wage Differentials and Segmentation: The Impact of Institutions and Changing Economic Conditions. European Journal of Industrial Relations, 24, 145-162. https://doi.org/10.1177/0959680120959008

Auriol, E. (2013). Barriers to Formal Entrepreneurship in Developing Countries. World Bank. https://openknowledge.worldbank.org/handle/10986/16364

Baumol, W. J. (2009). Small Enterprises, Large Firms and Growth. The Role of SMEs and Entrepreneurship in a Globalised Economy. In A. Lundström (Ed.), Ministry of Education and Research Sweden (pp. 59-72).

Baumol, W. J., Litan, R. E., \& Schramm, C. J. (2007). Good Capitalism, Bad Capitalism, and the Economics of Growth and Prosperity. https://ssrn.com/abstract=985843 https://doi.org/10.2139/ssrn.985843

Bennett, D. L., \& Nikolaev, B. (2019). Economic Freedom, Public Policy, and Entrepreneurship. In J. Gwartney, R. Lawson, J. Hall, \& R. Murphy (Eds.), Economic Freedom of the World: 2019 Edition (Fraser Institute, 2019, pp. 199-224).

Casson, M., \& Wadeson, N. (2007). Entrepreneurship and Macroeconomic Performance. Strategic Entrepreneurship Journal, 1, 239-262. https://doi.org/10.1002/sej.35

del Olmo-García, F., Crecente, F., \& Sarabia, M. (2020). Macroeconomic and Institutional Drivers of Early Failure among Self-Employed Entrepreneurs: An Analysis of the Euro Zone. Economic Research-Ekonomska Istraživanja, 33, 1830-1848. https://doi.org/10.1080/1331677X.2020.1754268

Devece, C., Peris-Ortiz, M., \& Rueda-Armengot, C. (2016). Entrepreneurship during Economic Crisis: Success Factors and Paths to Failure. Journal of Business Research, 69, 5366-5370. https://doi.org/10.1016/j.jbusres.2016.04.139

Enste, D., \& Schneider, F. (2003). Hiding in the Shadows: The Growth of the Underground Economy. Economic Issues No. 30, International Monetary Fund. https://doi.org/10.5089/9781589061521.051

Felsenthal, M. (2020). COVID-19 to Plunge Global Economy into Worst Recession since World War II. Press Release June 8, the World Bank.

Galindo-Martín, M., Castaño-Martínez, M., \& Méndez-Picazo, M. (2021). The Role of Entrepreneurship in Different Economic Phases. Journal of Business Research, 122, 171-179. https://doi.org/10.1016/j.jbusres.2020.08.050

Gindling, T. H., \& Newhouse, D. (2014). Self-Employment in the Developing World. World Development, 56, 313-331. https://doi.org/10.1016/j.worlddev.2013.03.003

Hagedoorn, J. (1996). Innovation and Entrepreneurship: Schumpeter Revisited. Industrial and Corporate Change, 5, 883-896. https://doi.org/10.1093/icc/5.3.883

Lall, S. (2001). Competitiveness Indices and Developing Countries: An Economic Evaluation of the Global Competitiveness Report. World Development, 29, 1501-1525. https://doi.org/10.1016/S0305-750X(01)00051-1

Lee, E. (2013). World Bank: World Development Report 2013: Jobs. Population and Development Review, 39, 353-355. https://doi.org/10.1111/j.1728-4457.2013.00598.x

Loayza, N., Servén, L., \& Sugawara, N. (2009). Informality in Latinamerica and the Caribbean (Vol. 4888). Washington DC: World Bank. 
Maritz, A., Perenyi, A., de Waal, G., \& Buck, C. (2020). Entrepreneurship as the Unsung Hero during the Current COVID-19 Economic Crisis: Australian Perspectives. Sustainability, 12, 4612. https://doi.org/10.3390/su12114612

Mendoza, G., Llopis, J., Gasco, J., \& Gonzalez, R. (2021). Entrepreneurship as Seen by Entrepreneurs in a Developing Country. Journal of Business Research, 123, 547-556. https://doi.org/10.1016/j.jbusres.2020.10.038

Omri, A. (2020). Formal versus Informal Entrepreneurship in Emerging Economies: The Roles of Governance and the Financial Sector. Journal of Business Research, 108, 277-290. https://doi.org/10.1016/j.jbusres.2019.11.027

Perry, G. E., Arias, O., Fajnzylber, P., Maloney, W. F., Mason, A., \& Saavedra-Chanduvi, J. (2007). Informality: Exit and Exclusion. World Bank Latin American and Caribbean Studies. World Bank. https://openknowledge.worldbank.org/handle/10986/6730 https://doi.org/10.1596/978-0-8213-7092-6

Quadrini, V. (2009). Entrepreneurship in Macroeconomics. Annals of Finance, 5, 295-311. https://doi.org/10.1007/s10436-008-0105-7

Schoar, A. (2009). The Divide between Subsistence and Transformational Entrepreneurship. Innovation Policy and the Economy, 10, 57-81. https://doi.org/10.1086/605853

Walia, A., \& Chetty, P. (2020). The Economic Theories of Entrepreneurship. Project Guru. https://www.projectguru.in/the-economic-theories-of-entrepreneurship

Wennekers, S., van Wennekers, A., Thurik, R., \& Reynolds, P. (2005). Nascent Entrepreneurship and the Level of Economic Development. Small Business Economics, 24, 293-309. https://doi.org/10.1007/s11187-005-1994-8

Workie, M., \& Hekelová, E. (2016). Is the Global Competitiveness Index Informative? CBU International Conference Proceedings, 4, 132-141.

https://doi.org/10.12955/cbup.v4.754 